\title{
Una grave complicación de embarazo molar embrionario
}

\author{
Doctores J. A. Gómez Palacino y Leopoldo Saavedra (*)
}

A. M., de veintiún años.

Natural de Manta. O. D.

Reside en Bogotá hace 4 años.

Sin antecedentes familiares o personales importantes.

Menarquia a los 15 años. Ciclo: $30 \times 3$, normal.

Antecedentes obstétricos: un parto a término, espontáneo, con feto vivo, hace 4 años.

Fecha de ingreso: julio 9 de 1956.

Motivo de consulta: dolor en bajo vientre y vómito.

Cuenta que hace 8 días "expulsó un par de niños como de $31 / 2$ meses". Dejó de sangrar y como se renovara luego la hemorragia acompañada de dolor, fue donde un médico quien le aconsejó la hospitalización.

$\mathrm{Al}$ examen se encuentra una paciente con estado general deficiente, muy pálida y con taquicardia, taquipnea, lengua saburral, T. A. de 110 x 60 y temperatura de 38.5 o C.

A la palpación abdominal se aprecia: dolor, principalmente en la zona hipogástrica y en ella una masa correspondiente al útero que asciende a 11 centímetros por encima del pubis.

Tacto vaginal: cuello posterior, cerrado y corto; su movilización es muy dolorosa. Fondos de saco ocupados, sin embargo, su apreciación es difícil por el dolor. Cuerpo uterino aumentado de tamaño. Hay una secreción purulenta y maloliente.

Se hace el diagnóstico de aborto séptico, anexitis y se instituye tratamiento con antibióticos para hacer más tarde raspado uterino.

(*) Jefes de Clínica Obstétrica del Instituto de Protección Materno-Inlantil C. V. A. 
Evolución.-En los días siguientes continuó la hipertermia con grandes oscilaciones, vómito, meteorismo, paresia intestinal, taquicardia, mal estado general y enflaquecimiento progresivo. Más tarde expulsó las vesículas correspondientes a una mola, acompañado este hecho de abundante hemorragia con estado general precario. Se practicó transfusión de sangre y de plasma y se hizo raspado uterino.

Posteriormente la sintomatología general se acentuó y en esas condiciones fue vista por nosotros. El estado general era lamentable: facies peritoneal, anemia intensa de piel y mucosas, lengua saburral, taquicardia, taquipnea, sudoración y ansiedad. A la palpación abdominal se apreció gran sensibilidad, defensa muscular. meteorismo en la parte superior y en el hipogastrio una mesa de contornos imprecisos y muy dolorosa.

El examen ginecológico reveló: cuello corto, cerrado, su movilización aumentaba el dolor; fondos de saco muy sensibles, tensos y ocupado el derecho por una masa de forma irregular, mamelonada y que resultaba imposible de apreciar si se continuaba o no con la masa hipogástrica. No era posible tampoco examinar el cuerpo del útero por la sensibilidad tan marcada.

Dagnóstico: 1) Foritonitis: a) por causa axtragenital?, b) de causa ginecológica?

Descartamos las causas extragenitales en vista de los antecedentes, la evolución propia del caso y los hallazgos de los repetidos exámenes clínicos practicados.

Por las mismas razones tuvimos en cuenta las causas ginecológicas como las desencadenantes del grave proceso peritoneal. Descartamos la posibilidad c'e una perforación uterina teniendo los datos suministrados personalmente por el médico que practicó el raspado uterino y en esas condiciones sospechamos, entre las causas anexiales inflamatorias, la posibilidad de una supuración de quistes ováricos luteínicos, basándonos entre otras razones, en la presencia de masas irregulares en los fondos de saco vaginales.

Conducta.-Decidimos mejorar el estado general en cuanto fuese posible para intervenirla luego. En las horas de la noche la paciente fue operada; la descripción de la intervención es la siguiente:

Laparotomía media infraumbilical. Peritonitis purulenta generalizada. Al explorar los anexos del útero se encuentran quistes ováricos izquierdos con contenido purulento drenando a la ca- 
vidad peritoneal. En ovario derecho grandes quistes multiloculares cuya transparencia permite observar líquido claro. Hay gran congestión del apéndice que se halla muy cerca del proceso purulento. En el fondo de saco de Douglas hay gran cantidad de pus. En las condiciones anteriores se liberan algunas adherencias al ovario supurado que presenta el epiplón; se practica salpingooforectomía izquierda y apendicectomía. La matriz congestionada, está ligeramente aumentada de tamaño pero sin lesiones macroscópicas. Por tratarse de quistes sin infección en ovario derecho, se respetan. Se dejan drenes contralaterales y se cierra la pared por planos poniendo seda en peritoneo y aponeurosis y agrafes en la piel.

Las piezas se enviaron a estudio anatomopatológico y el reporte respectivo dice lo siguiente:

"Descripción macroscópica.-El espécimen está constituído por una trompa de Falopio y una masa poliquística adherida a ella. La trompa mide $9 \times 0.5$ centímetros y no presenta cambios de importancia. La masa poliquística está constituída por múltiples quistes que miden entre 3 y 0.5 centímetros que se encuentran recubiertos por peritoneo. El peritoneo está a su vez recubierto por membranas de fibrina que se desprenden con dificultad. Hay zonas de hemorragia en la serosa. Las paredes de los quistes miden entre 0.1 y 0.3 centímetros de diámetro y en algunas de ellas se observa tejido que recuerda cuerpo lúteo. Algunas de las cavidades contienen pus de color cremoso y otras contienen material de aspecto gelatinoso. Se observa que en el área en donde convergen los quistes se encuentra tejido de aspecto ovárico. Adherido a la masa poliquística hay un fragmento de epiplón de 5 centímetros de diámetro que presenta franca evidencia de necrosis.

Se recibe, además, un apéndice vermiforme de 5.5 centímetros de longitud por 0.7 centímetros de diámetro; en él se ven membranas de fibrina sobre su superficie peritoneal.

Al corte no muestra cambios de importancia.

Descripción microscópica.-Los cortes muestran tejido ovárico congestionado con un cuerpo blanco, un fragmento fibro-grasoso infiltracio por una gran cantidad de leucocitos, especialmente polimorfonucleares y con formación de pequeños abscesos y apéndice vermiforme también infiltrado por una gran cantidad de leucocitos, especialmente polimorfonucleares, más numerosos en la capa serosa y en la parte exterior de las musculares. No hay evidencia 
de tuberculosis. En ningún sitio hay reacción decidual y no hay cuerpos lúteos reconocibles en el tejido ovárico".

Diagnóstico.-Posible anexitis subaguda purulenta con perianexitis y periapendicitis subagudas purulentas.

Comentario.-Hemos querido transcribir esta historia clínica porque la hemos encontrado interesante por varios aspectos: 1) la concomitancia de embarazo gemelar con la degeneración vesiculosa del corion; 2) la grave evolución del proceso séptico pese a la administración amplia de antibióticos; 3) la escasa frecuencia de esta complicación.

En cuanto al primer aspecto vale la pena decir que la presencia de embarazos gemelares con mola hidatidiforme es realmente escasa. Su comprobación es posible solamente en casos similares al presente.

Respecto a la evolución hemos de decir que no se incluye dentro de las complicaciones de un embarazo molar, el que los quistes luteínicos que con frecuencia la acompañan sufran procesos supurativos capaces de ocasionar una peritonitis. Se presentan, aesde luego, infecciones como ocurrirían en cualquier aborto incompleto. Sin embargo, hemos de tener en cuenta que una infección genital encuentra en estos casos las mejores condiciones de propagación como serían: congestión pelvigenital aumentada, modificaciones vasculares intensas, cambios tisulares, estado general deficiente por anemia, toxicosis, etc.

El tercer aspecto es su frecuencia; no hemos encontrado en la literatura nuestra el relato de casos como el que presentamos. Para ilustrar un poco este comentario con cifras, bastaría decir que en el curso de los últimos 5 años en el Instituto Materno-Infantil "Concepción Villaveces de Acosta", a donde han ingresado aproximadamente 60.000 pacientes en dicho lapso, es el único caso registrado. Este dato le confiere, en nuestro concepto, importancia al tema que hemos querido exponer con el fin de que se tenga en cuenta como una complicación más de las degeneraciones molares.

Finalmente hemos de agregar que la paciente salió del Instituto por recuperación después de una complicación post-operatoria que consistió en una flebitis del miembro inferior izquierdo después de una venoclisis. 